\title{
OS JOGOS PARA O ENSINO DE ARITMÉTICA NO MANUAL 'DIDÁTICA DA 1 SÉRIE’ DE AMARAL FONTOURA
}

\author{
GAMES TO TEACH ARITHMETIC IN 'DIDATICA DA $1{ }^{a}$ SÉRIE' BY AMARAL FONTOURA HANDBOOK
}

JUEGOS PARA ENSEÑAR ARITMÉTICA EN EL MANUAL 'DIDÁTICA DA $1^{a}$ SÉRIE' DE AMARAL FONTOURA

\author{
SCHNEIDER, Cintia ${ }^{1}$
}

COSTA, David Antonio da. ${ }^{2}$

\section{RESUMO}

Tem-se por objetivo compreender o papel dos jogos para o ensino de aritmética no manual pedagógico 'Didática da 1ª série', de autoria de Amaral Fontoura, de 1958. As análises utilizam aportes da história cultural (CHARTIER, 2010), privilegiando os manuais como fonte de pesquisa (VALENTE, 2008), além dos demais aportes da história da educação matemática. Fontoura foi um autor importante, principalmente na divulgação dos pressupostos da Escola Nova, através dos seus manuais. Fontoura cita, recorrentemente, os testes $A B C$ de Lourenço Filho, os centros de interesse, a importância da motivação e da competição. E todos estes aspectos podem ser alcançados, de acordo com o autor, com o uso dos jogos.

Palavras-chave: Amaral Fontoura. História da Educação Matemática. Jogos para o Ensino de Aritmética. Manual Pedagógico.

\section{ABSTRACT}

The objective is to understand the role of games for arithmetic teaching in the pedagogical handbook 'Didática da $1^{a}$ série' written by Amaral Fontoura in 1958. The analyzes use contributions from cultural history (CHARTIER, 2010) as a source of research (VALENTE, 2008), in addition to other contributions in the history of mathematical education. Fontoura was an important author, mainly in disseminating the Escola Nova assumptions through his handbooks. Fontoura repeatedly mentions Lourenço Filho's $A B C$ tests, centers of interest, the importance of motivation and competition. And all these aspects can be achieved, according to the author, with the use of games.

Keywords: Amaral Fontoura. History of mathematics education. Arithmetics teaching games. Textbook.

\section{RESUMEN}

El objetivo es comprender el papel de los juegos para la enseñanza de aritmética en el manual pedagógico 'Didática da $1^{a}$ série', escrito por Amaral Fontoura en 1958. Los análisis utilizados son contribuciones de la historia cultural (CHARTIER, 2010) como fuente de investigación (VALENTE, 2008), además de otras contribuciones en la historia de la educación matemática. Fontoura fue un autor importante, principalmente en la difusión de los supuestos de la Escola Nova a través de sus manuales. Fontoura menciona repetidamente los testes $A B C$ de Lourenço Filho, los centros de interés, la importancia de la motivación y la competencia. $Y$ todos estos aspectos se pueden lograr, según el autor, con el uso de juegos.

Palabras clave: Amaral Fontoura. Historia de la educación matemática. Juegos de enseñanza de aritmética. Manual pedagógico.

\footnotetext{
${ }^{1}$ Universidade Federal de Santa Catarina - UFSC - Brasil.

2 Universidade Federal de Santa Catarina - UFSC - Brasil.
} 


\title{
CONSIDERAÇÕES INICIAIS
}

O presente artigo apresenta alguns resultados da pesquisa de mestrado 3 inserida no campo da História da educação matemática. Esta dissertação de mestrado se integra às pesquisas realizadas pelo GHEMAT - Grupo de Pesquisa de História da Educação Matemática do Brasil $^{4}$ e do GHEMAT/SC 5 . De acordo com Valente (2007, p. 47), o GHEMAT tem por intenção "[...] alargar o entendimento de como se dá, na história, o processo de escolarização dos saberes e, em particular, da matemática, a partir de um instrumental teórico metodológico utilizado por historiadores".

O objetivo deste artigo é compreender o papel dos jogos para o ensino de aritmética no manual 'Didática Especial da 1ª série', de autoria de Amaral Fontoura.

Considerando os preceitos de Chartier (2010), referência da história cultural, acerca da relevância das condições e contextos de produção das fontes de pesquisa, aponta-se que o autor no manual a ser analisado, Amaral Fontoura, foi um nome importante no que diz respeito à autoria de livros didáticos destinados ao uso docente, inclusive sendo caracterizado como o autor que mais escreveu para professores (FRANÇA, 2016). Chartier (2010) afirma que o material impresso é um objeto primordial de investigação e é preciso considerar de que maneira as pessoas fazem uso destes objetos e como os mesmos são difundidos.

Fontoura foi um dos autores do período responsável por divulgar os preceitos do Movimento da Escola Nova no Brasil, cujo Movimento se revelou diferentemente ao de outros países. Apesar de seguir pressupostos similares, houve uma proposta de política educacional que discutia a defesa de uma escola laica, comum a todos e prerrogativa do Estado (VIDAL, 2003). Ainda,

\begin{abstract}
A Escola Nova concebe a aprendizagem como um processo de aquisição individual, segundo condições personalíssimas de cada discípulo. Os alunos são levados a aprender observando, pesquisando, perguntando, trabalhando, construindo, pensando e resolvendo situações problemáticas que Ihes sejam apresentadas, quer em relação a um ambiente de coisas, de objetos e ações práticas, quer em situações de sentido social e moral, mediante ações simbólicas. (LOURENÇO FILHO, 1978, p. 151).
\end{abstract}

\footnotetext{
${ }^{3}$ SCHNEIDER, Cintia. Os jogos para o ensino de aritmética em manuais pedagógicos de 1930-1960 no Brasil. 203 f. Dissertação (Mestrado em Educação Cientifica e Tecnológica) - Universidade Federal de Santa Catarina, Florianópolis, 2017. Disponível em: <https://repositorio.ufsc.br/handle/123456789/181816>. Acesso em: 18 jan. 2018.

${ }^{4}$ Na página on-line do GHEMAT Brasil (http://www2.unifesp.br/centros/ghemat/paginas/about_ghemat.htm), encontram-se mais informações de que foi criado no ano de 2000 e é liderado pelos professores Wagner Rodrigues Valente da UNIFESP (Universidade Federal de São Paulo) e Neuza Bertoni Pinto, vinculada à REAMEC (Rede Amazônica de Educação em Ciências e Matemática) e está credenciado no diretório de Grupos de Pesquisa do CNPq. O grupo reúne pesquisadores de variadas universidades e estados brasileiros, mais precisamente, de acordo com levantamento realizado em 2016, são 35 pesquisadores e 87 estudantes, sendo estes (estudantes) de mestrados profissionalizantes e acadêmicos, doutorados e alunos de graduação.

${ }^{5}$ O GHEMAT/SC foi institucionalizado no segundo semestre de 2017 e tem como líder o professor Dr. David Antonio da Costa e vice-líder a professora Dra. lara Zimmer. Atualmente conta com sete pesquisadores, entre eles, alunos de graduação, mestrado e doutorado da UFSC. Disponível em: <http://dgp.cnpq.br/dgp/espelhogrupo/2464392240898492>. Acesso em: 25 jul. 2017.
} 
Sabe-se da importância de definir o que é um manual pedagógico, visto sua notoriedade neste artigo. Uma forma de defini-los é de que se tratam de livros didáticos destinados ao uso do professor, seja em sua formação para posterior atuação docente ou exatamente na sua atuação como professor. Enquanto o livro didático apresenta proposições de exercícios e problemas aos alunos, o manual pedagógico abrange aspectos pedagógicos e metodológicos do ensino.

Valente (2008, p. 142) aponta que "[...] os livros didáticos constituem-se em elementos fundamentais para a pesquisa do trajeto histórico da educação matemática. Livro didático e educação matemática parecem ser elementos indissociáveis".

E como o jogo para o ensino de aritmética ${ }^{6}$ é caracterizado por Amaral Fontoura? Contemporaneamente, o jogo é uma forma de tornar o ensino de matemática mais interessante e ainda um meio de aproximar os conteúdos da realidade do aluno. Moura (1999, p. 86) indica que "A matemática deve buscar no jogo (com sentido amplo) a ludicidade das soluções construídas para as situações-problema seriamente vividas pelo homem", unindo assim, o prazer proporcionado pelos jogos com situações cotidianas. Neste artigo, quer-se verificar como Amaral Fontoura aborda o jogo em seu manual 'Didática da $1^{\text {a }}$ Série'.

Ao realizar revisão bibliográfica objetivando encontrar trabalhos na área que se assemelhavam ou pudessem colaborar com este artigo, utilizou-se o banco de tese e dissertações da Capes e a pasta 'Teses e Dissertações em História da educação matemática' do RCD7. Percebeu-se que há muitas pesquisas no campo da História da educação matemática e dessas, inúmeras fazem análise em manuais. Destaca-se a dissertação de Lacava (2017), na qual a autora analisou as diferentes abordagens da prova dos nove em livros didáticos em tempos de grupos escolares em Santa Catarina, mais especificamente de 1890 a 1970. Como considerações, Lacava (2017), cita que pôde compreender que a prova dos nove se associava a diversos conteúdos matemáticos, dentre eles, operações aritméticas, divisibilidade, decomposição decimal, e outros. O referido trabalho é importante, haja vista que, além de fazer parte da História da educação matemática, a forma como a autora analisou os livros didáticos auxiliaram na decisão do caminho de análise adotado neste artigo.

Ao buscar por pesquisas que tratassem de jogos para o ensino de aritmética, encontraram-se algumas dificuldades e, por conta disso, optou-se por utilizar a nomenclatura de jogos matemáticos ou simplesmente, jogos. Houve muitos retornos, porém, poucos tratavam devidamente de assuntos próximos ao em questão. Inclusive não foi encontrado nenhum trabalho que se ocupasse dos jogos

\footnotetext{
${ }^{6}$ Enfatiza-se que se optou pela nomenclatura de 'jogos para o ensino de matemática/aritmética' ao invés de jogos de matemática/aritmética, com vistas que não há jogos de matemática/aritmética, há jogos que podem ser aplicados no ensino de matemática/aritmética. Considera-se jogo a atividade indicada pelo autor do manual.

${ }^{7}$ Repositório de Conteúdo Digital - RCD: está situado 'fisicamente' na Universidade Federal de Santa Catarina, no qual são alocados diversos documentos digitalizados (livros, legislações, cadernos, revistas...) encontrados por pesquisadores do GHEMAT de todo Brasil. Essa base de documentos, disponível por acesso aberto pela internet, tem se mostrado profícua para a realização de estudos histórico-comparativos relativos à circulação de modelos pedagógicos, permitindo o estabelecimento do diálogo entre os pesquisadores nos seus diversos locais de pesquisa (COSTA; VALENTE, 2015). Disponível em <https://repositorio.ufsc.br/handle/123456789/1791>. Acesso em 15 jan. 2018.
} 
para o ensino de aritmética no âmbito da história da educação matemática, como nesse artigo, nem mesmo em manuais pedagógicos.

Destaca-se na dissertação de Elorza (2013), um levantamento de teses e dissertações que tratam de jogos no ensino e aprendizagem de matemática nos anos iniciais do ensino fundamental. Como recorte temporal, a autora adotou o período de 1991 a 2010 e encontrou 303 trabalhos no banco de teses e dissertações da CAPES, em cujos títulos e/ou resumos mencionassem os jogos, porém apenas 23 dissertações e teses se referiam aos anos iniciais do ensino fundamental e jogos relacionados a conteúdos matemáticos e foram esses os trabalhos analisados com maior profundidade. Como considerações, Elorza (2013), ressalta que a maioria das pesquisas aponta para a necessidade de revisão dos cursos de formação de professores, visto que a grande parte dos professores das séries iniciais do ensino fundamental não sabe lidar com metodologias de ensino diferenciadas. Além disso, as pesquisas analisadas abordam e compreendem o jogo no espaço escolar como uma possibilidade de mudança do processo de ensino e aprendizagem de Matemática nas escolas e convergem para a ideia de que os jogos auxiliam no rendimento/desenvolvimento cognitivo dos alunos e contribuem para mudanças em relação à prática docente.

Como apêndice, Elorza (2013), traz uma tabela com todas as 303 dissertações e teses pesquisadas, com detalhes sobre a área de concentração, sujeitos, coleta de dados e abordagem. Averiguou-se que apenas duas pesquisas tratam de jogos em uma perspectiva histórica, sendo elas a dissertação de Santos (2004), que propõe refletir e compreender o papel dos jogos e da brincadeira a partir das perspectivas educacionais da criança no início dos tempos modernos, porém se ocupa da educação infantil e jogos de forma geral. A segunda e última pesquisa, em uma perspectiva histórica do total de 303 levantadas por Elorza (2013), é a dissertação de Santos (2006), que discorre sobre a história dos jogos escolares no município de Sorocaba em meados do século $X X$, cujo foco da pesquisa foram os jogos físicos, desenvolvidos em competições escolares. Tanto em Santos (2004), quanto em Santos (2006), os jogos abordados são de outra natureza, diversa à aritmética/matemática. Portanto, dentre as 303 pesquisas levantadas por Elorza (2013), que se referiram a jogos, não há nenhuma que trate de jogos em aritmética na perspectiva histórica.

Em virtude do que foi mencionado, evidencia-se uma lacuna de pesquisas que tratem dos jogos para o ensino de aritmética em manuais pedagógicos no âmbito da História da educação matemática e, por conta disso, a revisão de literature se torna justificável para a escrita deste artigo.

\section{AMARAL FONTOURA}

Amaral Fontoura8, nascido em 1942 e falecido em 1982, foi um dos autores que mais publicou para professores (FRANÇA, 2016). Lê-se no próprio manual que ele foi Professor da Pontifícia Universidade Católica do Rio de Janeiro, da Universidade do Estado do Rio, da Faculdade de Serviço Social do Distrito Federal, Chefe do Departamento de Sociologia de Ciências Sociais, além de técnico

\footnotetext{
${ }^{8}$ Por vezes denominado Afro do Amaral Fontoura, por vezes, apenas Amaral Fontoura. No manual analisado ele se denomina como Amaral Fontoura e por isso, opta-se pelo uso dessa nomenclatura.
} 
de Educação, delegado do governo junto a várias Escolas Normais, professor de inúmeros cursos de aperfeiçoamento. Destaca-se, ainda, que Amaral Fontoura foi o diretor da Biblioteca Didática Brasileira, sobre a qual será dissertado adiante. França caracteriza Fontoura como:

\begin{abstract}
Amaral Fontoura foi um autor expressivo no período, divulgando os princípios da Escola Nova em publicações da Editora Aurora, com coleções de manuais pedagógicos destinados à formação de professores, com diversas edições e grandes tiragens, com um discurso que apresentava preocupações com a formação de professors. (FRANÇA, 2012, p. 2).
\end{abstract}

França (2012) é constante na afirmação que Fontoura seguia os pressupostos escolanovistas, principalmente no que concerne ao interesse dos alunos e aos centros de interesse. Para isso, nos manuais do autor se observam metodologias que valorizavam a experiência, observação, cooperação, e atividades como excursões e jogos.

No Movimento da Escola Nova, cabia aos educadores considerarem o interesse dos alunos, que, de acordo com Cunha (1994), é a primeira condição para que a criança desenvolva uma atividade espontaneamente.

Ainda sobre o Movimento da Escola Nova, os intelectuais envolvidos objetivavam a construção do Brasil como uma nação. $E$ foi exatamente na educação que esses intelectuais viram a possibilidade de incorporar a população brasileira ao processo de construção da nação (como novos cidadãos), e também, como uma forma de criar condições de alargamento do mercado cultural. Mas, para que o campo educacional se tornasse um espaço social, era necessário que houvesse uma estruturação das associações profissionais na formação e profissionalização dos professores, na produção de conhecimentos técnicos e teóricos e na construção de um sistema de ensino (SGANDERLA, 2007). E foi por esta estruturação que os Pioneiros da Escola Nova lutaram.

Apesar de, na década de 1950, estar em ascensão o Movimento da Matemática Moderna, os livros deste período, como o caso do manual analisado, não contemplavam tais avanços, pois, ainda eram influenciados pelas propostas do Movimento da Escola Nova. Até porque não existe uma ruptura completa com os antigos valores culturais ao iniciar uma nova fase de reforma.

Figura 1: Amaral Fontoura 


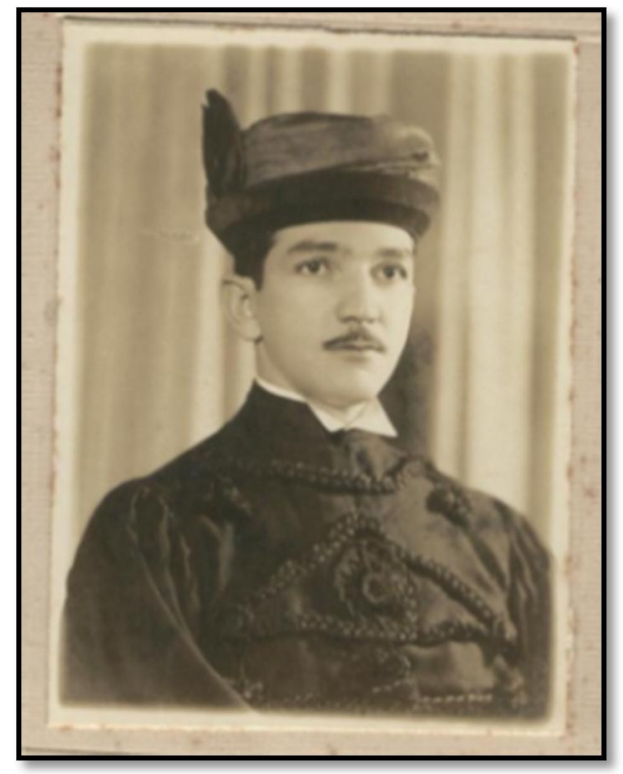

Fonte: Disponível em <http://blog.msmacom.com.br/amaral-fontoura/>. Acesso em: 10 jun.2017.

Maciel, Vieira e Souza (2012) indicam a dificuldade em encontrar informações sobre Amaral Fontoura. Das poucas obtidas por estes autores, destaca-se que ele foi responsável pelo I Congresso Brasileiro de Ensino Normal, ocorrido no Rio de Janeiro em 1966 e, durante a década de 1960, foi Presidente da Associação Brasileira das Escolas Normais, evidenciando seu expressivo envolvimento com a Escola Normal.

No manual 'Didática especial da $1^{\text {a }}$ série', encontram-se outras obras de Amaral Fontoura para a Biblioteca Didática Brasileira, em que se percebe uma vasta produção. São de autoria dele quatro edições do manual 'Fundamentos de educação', cinco edições da obra 'Sociologia Educacional', quatro edições da 'Metodologia do ensino primário', duas edições da 'Psicologia Educacional'. Ainda há indicação de obras em preparo, as quais versam sobre a educação rural, prática de ensino, ensino normal e testes. Todos estes manuais foram publicados pela Editora Aurora. As obras finalizadas datam de 1949 a 1958, demonstrando a dedicação do autor em escrever manuais destinados ao ensino e variando as temáticas centrais, transpassando pela metodologia, psicologia, sociologia, fundamentos e didática da educação.

Além dos manuais escritos por Amaral Fontoura para a Biblioteca Didática Brasileira, são citadas outras obras dele, sendo a maioria dessas editada pela Livraria Globo, as quais se referem à sociologia e questões relacionadas ao campo. Maciel, Vieira e Souza (2012), apontam como destaque do autor, exatamente, a produção de manuais pedagógicos nos anos de 1920 a 1940, e citam que, por décadas, eram adotados manuais estrangeiros no Brasil, mas com o surgimento da indústria editorial brasileira houve a nacionalização dos manuais usados nas escolas e, dentre os que tiveram circulação notável, encontram-se os de Amaral Fontoura.

A relevância desse manual remonta exatamente no fato dele fazer parte de uma das séries da Biblioteca Didática Brasileira. No manual há um tópico específico sobre a Biblioteca Didática Brasileira escrito pela Editora Aurora ${ }^{9}$, em que se justifica a necessidade de uma Renovação Educacional no

\footnotetext{
${ }^{9} \mathrm{Em}$ todos os manuais das séries da Biblioteca Didática Brasileira há esse tópico (MACIEL; VIEIRA; SOUZA, 2012).
} 
Brasil, para tornar a escola mais viva, dinâmica, ligada à realidade e que permita que os alunos sejam capacitados a trabalhar pelo progresso nacional. Nesse sentido, a educação é tratada como a solução para criar melhores condições de vida. Mais especificamente, é citada a necessidade de "preparar professores cada vez mais eficientes" (p. 11). Além disso, Fontoura (1958, p. 11) aponta que "Não há exagêro em afirmar que nas mãos do professor primário reside uma das maiores esperanças de dias melhores para o Brasil. Daí a alta responsabilidade das Escolas Normais - as escolas que formam tais professores".

Apesar de citar que através dos professores e, consequentemente, na formação de professores nos Cursos Normais estaria a solução para a Renovação Escolar, adverte-se a dificuldade em renovar o ensino com o uso de livros antiquados, com predominância de teorias e pouco práticos. Nesse sentido, uma das maiores dificuldades das Escolas Normais para promover essa renovação era a falta de livros com o espírito de "Educação Renovada" (FONTOURA 1958, p. 11).

É exatamente nessa dificuldade que se criou a Biblioteca Didática Brasileira, destinada à produção de manuais, principalmente para o Ensino Normal, que abordassem o espírito renovador, objetivo e prático.

A Editora Aurora, responsável pela publicação dos manuais da Biblioteca Didática Brasileira, ficou sob direção de Amaral Fontoura, que conseguiu "[...] reunir duas qualidades que raramente se encontram juntas: profundo conhecimento teórico da Pedagogia, ao lado de um admirável espírito prático, objetivo" (FONTOURA, 1958, p.12). Dessa forma, a Biblioteca Didática Brasileira foi uma coleção de livros, que além de ensinar o que fazer, também ensinava como fazer, e tudo isso sob uma ótica de equilíbrio entre a "escola velha" e os exageros da "escola nova".

As obras da Biblioteca Didática Brasileira se reuniram em quatro séries: "A escola viva"10, "Legislação do ensino e textos escolares", Livro texto para as crianças" e "Como aprender brincando...".

\section{JOGOS PARA O ENSINO DE ARITMÉTICA NO MANUAL 'DIDÁTICA ESPECIAL DA 1ª SÉRIE'}

O manual em análise é datado do ano de 1958 e publicado pela Gráfica Editora Aurora. Este é o sexto volume da série I, nomeado 'A escola Viva' da Biblioteca Didática Brasileira.

Figura 2: Capa do manual 'Didática Especial da $1^{\text {a }}$ série'

\footnotetext{
${ }^{10}$ Nesta série se encontra o manual analisado neste tópico. 


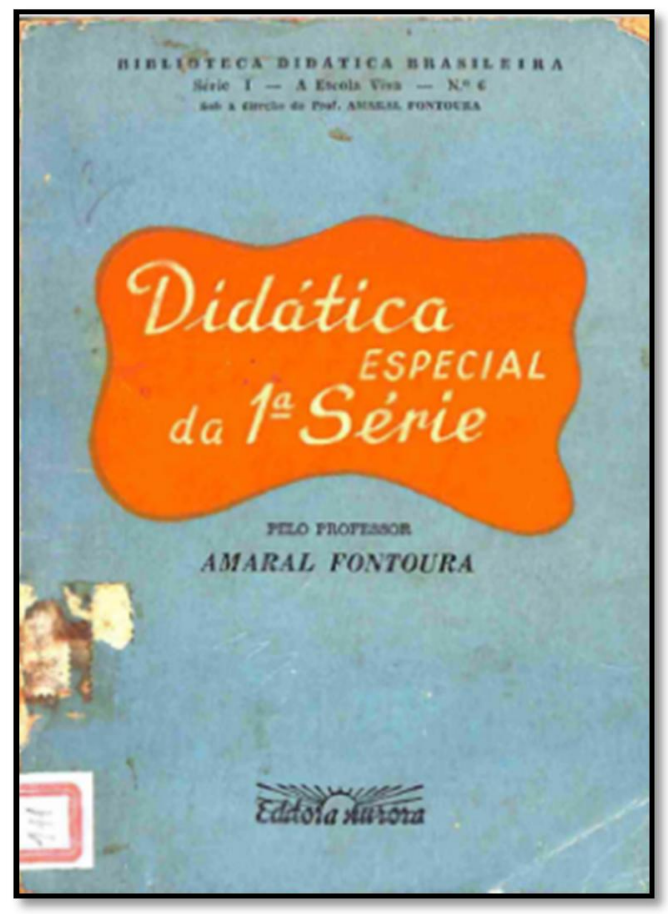

Fonte: Fontoura (1958).

Fica evidente, logo no início, que Amaral indica sua intenção com o manual de "tornar mais VIVA ${ }^{11}$ a Escola e mais OBJETIVO o Ensino Primário" (FONTOURA, 1958, p. 7). Desde aquele momento já se infere, como apontado por França (2016), a influência escolanovista no manual. Com isso, o exemplar é dividido em dois módulos: Parte Teórica e Parte Prática, que se desdobram em muitos outros itens.

Voltando-se ao foco principal desta pesquisa, que são os jogos para o ensino de aritmética, a primeira menção a este tema - neste momento, tratam-se de jogos para o ensino de forma geral - é na introdução, quando Fontoura (1958) aponta a relevância de ensinar brincando, visto que a $1^{\text {a }}$ série é a mais importante do currículo escolar, e a que exige mais cuidado por ser o primeiro contato da criança com a escola. De acordo com o autor, deve-se ensinar brincando como uma forma de criar uma ponte entre o lar e a escola, porém não se pode perder o caráter de aprendizagem.

Fontoura remete-se, a todo o momento, aos princípios da escola viva, afirmando que estes se fazem relevantes em todos os níveis de ensino, mas na $1^{\text {a }}$ série são um "imperativo absoluto" (FONTOURA, 1958, p. 17), isso por que "A escola viva serve para socializar rapidamente a criança. A escola viva, bem aplicada, aumenta cem por cento o aproveitamento ou rendimento escolar" (FONTOURA, 1958, p. 17).

Destaca-se que ao final da introdução, ele faz um pedido a quem for usar o manual, inclusive citando os jogos: "Caro colega: faça escola viva e comunique-nos seus resultados. Mande-nos sugestões a respeito de jogos e brinquedos didáticos, que teremos prazer em publicar nas futuras edições, fazendo, assim com que sua experiência vá beneficiar a inúmeros outros professôres, espalhados: por êsse Brasil afora". (FONTOURA, 1958, p. 19).

\footnotetext{
${ }^{11}$ A expressão Escola Viva é atribuída à Édouard Claparède, usada por Fontoura como sinônimo de Escola Ativa, que, por sua vez, é a forma de realizar a Escola Nova (MACIEL; VIEIRA; SOUZA, 2012).
} 
Por muitas vezes, Fontoura critica os métodos de ensino que resultaram de um descompasso entre a escola e a vida e afirma que ouvir e repetir não é um método de ensino eficaz. A educação deveria se compor por oito aspectos: Educação da saúde, moral, social, econômica, cívica e política, estética, religiosa e intelectual. Para que isso ocorra de forma eficaz, é preciso que o ensino seja ativo. Com ensino ativo e, por sua vez, escola ativa, Fontoura diferencia que educar não é encher a criança com nomes e números, mantê-la quieta e imóvel. Em contraponto a isso, ele cita quatro características do ensino ativo, dentre elas, a Escola Viva seria aquela em que o professor interage com os alunos e não apenas 'dá aula'; Escola Viva é sinônimo de escola bonita, alegre, com alunos vivos e ativos que participam da vida na escola; Escola Viva seria aquela que representa uma escola em miniatura ${ }^{12}$, de modo geral, a "Escola Viva é a escola onde os alunos vão, não porque 'papai obriga' mas porque aí sentem prazer. É a escola onde as crianças se sentem felizes”. (FONTOURA, 1958, p. 23). A escola é vista como um lar bem organizado.

Apesar de não citar, diretamente os jogos, Fontoura cita as leis da aprendizagem, doze no total, porém, salientam-se duas: a lei do interesse e a lei da afetividade. A primeira diz respeito à necessidade do aluno estar interessado para aprender, a importância da motivação. E a segunda se refere ao fato de que o aluno aprende mais depressa o que Ihe agrada. Nesse item, Fontoura faz referência à lei hedônica de Thorndike "os indivíduos tendem a repetir, e, portanto, a aprender as reações que em geral são agradáveis e a não repetir, e, portanto não aprender as reações que em geral são desagradáveis" (FONTOURA, 1958, p.32). Além de destacar que ao citar Thorndike e mais adiante Lourenço Filho - Testes ABC- o autor se liga expressivamente aos princípios da Escola Nova, aponta-se que ambas as leis citadas se atrelam ao uso de jogos pedagógicos.

Os jogos para o ensino voltam a ser citados como meios de se promover a aprendizagem ideativa ou intelectual. São apontados jogos recreativos, jogos educativos e jogos musicados. Interessante observar que Fontoura separa os recreativos dos educativos, porém não justifica isso. Assim, buscou-se em Albuquerque (1958), outra importante autora contemporânea a Amaral Fontoura que se dedicou a escrever sobre o uso de jogos no ensino de matemática (SCHNEIDER, 2017). De acordo com Albuquerque (1958), os jogos recreativos são aqueles que se aproximam de um brinquedo ou brincadeira. Um exemplo de jogo recreativo seria aplicar um jogo de $1^{a}$ série para um aluno de $2^{a}$ série. Com isso, o jogo não teria aspecto efetivamente educativo, visto que o aluno, em tese, já domina os conteúdos acordados nesse jogo.

Por vezes, Fontoura indica os jogos como atividades a desenvolver com os alunos imaturos ${ }^{13}$, dentre estes, há os de encaixe, que são citados como "[...] a mais destacada função da Escola Ativa: servem para numerosos jogos sôbre Linguagem - Matemática - Geografia, etc" (FONTOURA, 1958, p. 49). Esta é uma característica também citada por Albuquerque (1958), pois sendo o jogo de fácil adaptação para outros conteúdos e matérias, facilita o trabalho do professor.

Outro jogo mencionado no manual é o 'Jogo do reconhecimento' - imagem a seguir -, que deve ser aplicado no início da aprendizagem, após o período de adaptação. Há uma descrição geral de

\footnotetext{
${ }^{12}$ Fontoura referencia Dewey nesta passagem.

${ }^{13}$ Que deveriam ser assim avaliados (maturos e imaturos) de acordo com o resultado dos Testes ABC.
} 
como aplicá-lo, de acordo com a figura 3, a seguir. Percebe-se que esse jogo possui a característica escolanovista de que o ele seja adaptável para diferentes conteúdos e matérias.

Figura 3: Jogo do reconhecimento

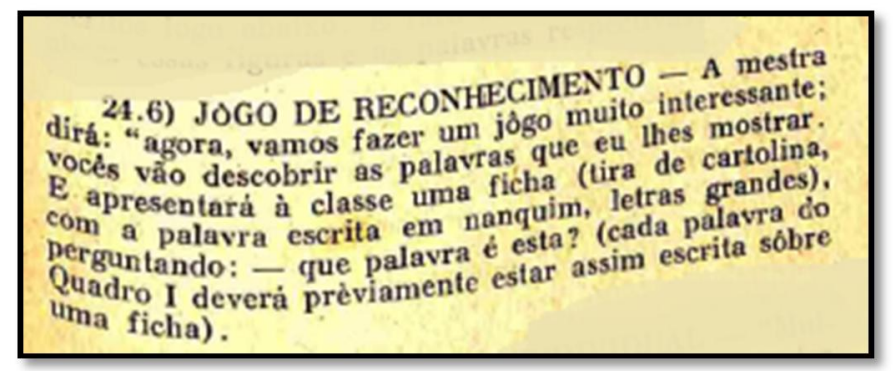

Fonte: Fontoura (1958, p. 63).

Ainda há um tópico que trata dos jogos didáticos como um meio de iniciar a aprendizagem. Nesse item são citados os jogos de víspora ou loto, para que a criança faça o reconhecimento de formas, figuras ou cores. São os chamados jogos preparatórios. Não há informações de como os aplicar ou produzir, porém o autor faz referência a outro manual de sua autoria 'Metodologia do ensino primário' em que eles estão explicitados. Interessante apontar que o jogo da víspora também é indicado por Irene de Albuquerque, em seu manual 'Jogos e Recreações Matemáticas', de 1958. Com isso, infere-se que esse jogo foi fortemente difundido à época, por meio de manuais pedagógicos (SCHNEIDER, 2017).

Nesse mesmo tópico, apesar de ter a prerrogativa de apresentar jogos para iniciar a aprendizagem, ainda são indicados o dominó, o jogo do aquário e reconstrução de gravuras. Esses jogos trazem a prerrogativa de exercitar conteúdos já vistos, ou então, a leitura. Da mesma forma, há ainda a motivação por envolver competições.

No tópico sobre a aprendizagem da leitura, Fontoura, apresenta alguns jogos para a fixação de aprendizagem, dentre eles, reconhecimento de palavras, reconstrução de gravuras, aquário. Fontoura (1958) sugere que sejam comprados dominós e baralhos educativos da Companhia Melhoramentos de São Paulo. Apesar do assunto central deste artigo serem os jogos para o ensino de aritmética, expõem-se, como no caso deste manual, jogos pedagógicos de forma geral, pois como Fontoura e os preceitos escolanovistas pregam, eles devem ser de fácil adaptação, inclusive para a aritmética. $\mathrm{Na}$ Figura 4, a seguir, o exemplo de um jogo que tinha por objetivo o reconhecimento das palavras:

Figura 4: Jogo do Reconhecimento de palavras 


\title{
lavras 28.3$)$ PRIMEIRO JoGo \\ figurinhas pregadino receberá Reconhecimento de pa- \\ vras escritas. \\ cada palavra sôbógo consistirá eme, com várias pala- \\ possivel fazer sôbre a respectiva figu criança colocar \\ de várias palo contrário: cada fa figura. Também é \\ figurinhas, que 0 aluno $(6)$ e no envelopterá o nome \\ correspondente. Os ono deverá colocor ene estarão as \\ no jôgo de lôto Os cartỏes deverăo ser sôbre a palavra \\ To vispora.
}

Fonte: Fontoura (1958, p. 72).

Apenas a última unidade do manual é destinada a aspectos matemáticos, mas mesmo assim, a matemática está inserida juntamente com o desenho e trabalhos manuais. Ao observar a assimetria no número de páginas destinadas à matemática (menos de quatro páginas) e nas destinadas à leitura e escrita (19 páginas), infere-se a valorização da leitura e escrita em comparação com a matemática.

Há indicação de que o ensino de matemática e de conhecimentos gerais deve ser absolutamente concreto e visual. Não devem ser apresentadas definições, regras e memorizações, tampouco as aulas de matemática devem ser separadas. Elas devem ser integradas às de conhecimento gerais, resultando assim em um ensino globalizante.

Os jogos para o ensino de matemática devem ser aplicados diariamente, tais como "corrida de cavalos", "jogo da glória", "colheita de frutas". Novamente não há descrição dos mesmos, apenas indicação de que estão explicados detalhadamente no manual de metodologia.

Diferente do que é indicado à leitura e escrita, em que há jogos preparatórios, para a matemática há apenas indicação de jogos de fixação. Percebe-se que a única exigência para que uma atividade se torne um jogo, é que tenha competição. Isso é evidenciado na citação abaixo:

\begin{abstract}
Qualquer operação matemática pode ser transformada em interessante jôgo, desde que a professôra chame ao quadro-negro várias crianças ao mesmo tempo e os mande fazer a conta, dizendo: "vamos ver quem vai terminar mais depressa e certo, quem vai ser o campeão das contas". Os alunos poderão também, ser divididos em dois partidos, sendo chamados dois a dois ao quadro, para fazerem as contas, ganhando ponto o partido cujo componente terminar a conta primeiro e certo. (FONTOURA, 1958, p. 74).
\end{abstract}

\section{CONSIDERAÇÕES FINAIS}

Realizar pesquisas sobre a história da educação matemática, utilizando os manuais pedagógicos como fontes de pesquisa, permitem com que se construa uma representação do que acontecia em outros tempos. Neste sentido, o objetivo deste artigo foi compreender qual o papel dos jogos para o ensino de aritmética no Manual 'Didática da 1ª série', de Amaral Fontoura. 
Amaral Fontoura foi um autor relevante, quando o assunto se trata de escrita de manuais didáticos, inclusive sendo ele diretor da Biblioteca Didática Brasileira. Além disso, sua obra disseminou os pressupostos do Movimento da Escola Nova no Brasil para os professores na época.

Os apontamentos indicados se evidenciam ao analisar o manual 'Didática da $1^{\text {a }}$ série', inclusive os jogos para o ensino de aritmética neste manual. Fontoura cita, recorrentemente, os testes $A B C$ de Lourenço Filho, os centros de interesse, a importância do aluno estar motivado, a importância da competição. $E$ todos estes aspectos podem ser alcançados com o uso dos jogos.

A prerrogativa do Movimento e, consequentemente, de Amaral Fontoura, era de que a criança estivesse no centro do processo de ensino e aprendizagem e que, estando motivada, aprendesse os conteúdos estabelecidos. Exatamente na preocupação da criança estar no centro e motivada é que a Psicologia se torna um importante aliado do Movimento, afinal "Coube à Psicologia, devido aos conhecimentos que traz a respeito da criança, a responsabilidade pela ênfase na organização de programas de ensino que levassem em conta os aspectos psicológicos, os interesses e as necessidades dos educandos" (CUNHA, 1994, p. 65).

A proposta escolanovista era exatamente "[...] atender, fundamentalmente, às exigências do desenvolvimento da criança" (CUNHA, 1994, p. 66) e para tal, fazia-se como premissa que a criança deveria ser motivada a aprender. Com isso, cabia aos educadores considerarem o interesse, que de acordo com Cunha (1994), é a primeira condição para que a criança desenvolva uma atividade espontaneamente. O que se verifica nos manuais é exatamente o jogo como uma das formas de motivar as crianças a aprenderem aritmética.

Há muitos exemplos na obra de Amaral Fontoura, e as análises dos jogos no manual revelam que o autor os abordava em consonância com os pressupostos escolanovistas.

\section{REFERÊNCIAS}

1. AlBUQUERQUE, I. Jogos e Recreações Matemáticas. v.1, 3 ed. Rio de Janeiro: Conquista, 1958. Disponível em: <https://repositorio.ufsc.br/handle/123456789/161042>. Acesso em: 22 jun. 2016.

COSTA, D. A; VALENTE, W. R. O repositório de conteúdo digital nas pesquisas de história da educação matemática. Rev. Iberoam. Patrim. Histórico-Educativo, Campinas (SP), v. 1, n. 1, p. 96-110, jul./dez. 2015.

4. CUNHA, N. H. S. Brinquedoteca: um mergulho no brincar. 2a ${ }^{a}$ ed. São Paulo: Maltese, 1994.

5. ELORZA, N. S. L. O uso de jogos no ensino e aprendizagem de Matemática nos anos iniciais do Ensino Fundamental: levantamento de teses e dissertações. 2013. 138 f. Dissertação (Mestrado) - 
Mestrado em Educação, Faculdade de Ciências e Tecnologia, Universidade Estadual Paulista. Presidente Prudente, 2013.

FONTOURA, A. A. Didática Especial da 1a série, v.6. Rio de Janeiro: Gráfica Aurora, 1958. Disponível em: <https://repositorio.ufsc.br/handle/123456789/159573>. Acesso em 22.set.2016.

7. FRANÇA, D. M. A. Biblioteca didática brasileira: o manual de testes e as propostas escolanovistas em cursos de formação de professores (1950-1970). REMATEC, Universidade Federal do Rio Grande do Norte, v. 23, p. 38-51, 2016.

LACAVA, A. G. Um estudo sobre diferentes abordagens da prova dos nove presentes em livros didáticos de aritmética (1890-1970). 2017. 159 f. Dissertação (Mestrado) - Mestrado em Educação Científica e Tecnológica, Universidade Federal da Santa Catarina, Florianópolis, 2017.

9. LOURENÇO FILHO, M. B. Introdução ao estudo da escola nova: bases, sistemas e diretrizes da pedagogia contemporânea. São Paulo: Melhoramentos, 1978. MACIEL, L. S. B; VIEIRA, R. A; SOUZA, F. C. L. Afro do Amaral Fontoura: Estudos, produções e a escola viva. Revista HISTEDBR On-line, Campinas, n.47, p.232-250, Set/ 2012.

11. MOURA, M. O. de. A série busca no jogo: do lúdico na Matemática. In: KISHIMOTO, T. M (organizadora). Jogo, Brinquedo, brincadeira e a educação. 3 ed. São Paulo: Cortez, 1999.

EANT. História dos jogos escolares do município de Sorocaba em meados do século XX. 2006. 147 f. Dissertação (Mestrado) - Mestrado em Educação, Universidade de Sorocaba, Sorocaba, São Paulo, 2006.

13. SANTOS, G. F. L. A infância, o jogo e a brincadeira: perspectivas educacionais da criança no início dos tempos modernos. 2004. 142 f. Dissertação (Mestrado) - Mestrado em Educação, universidade Estadual de Maringá, Maringá, Paraná, 2004.

SCHNEIDER, Cintia. Os jogos para o ensino de aritmética em manuais pedagógicos de 1930-1960 no Brasil. 203 f. Dissertação (Mestrado em Educação Cientifica e Tecnológica) - Universidade Federal de Santa Catarina, $\quad$ Florianópolis, $2017 . \quad$ Disponível em: <https://repositorio.ufsc.br/handle/123456789/181816>. Acesso em: 18 jan. 2018. Base Científica da Organização Escolar. 2007. 120 f. Dissertação (Mestrado) - Mestrado em Educação, Centro de Educação, Universidade Federal da Santa Catarina, Florianópolis, 2007. 
VALENTE, W, R. História da Educação Matemática: interrogações metodológicas. REVEMAT- Revista Eletrônica de Educação Matemática. v. 2, p.28-49, UFSC, 2007.

17. VALENTE, W. R. Livro didático e educação matemática: uma história inseparável. ZETETIKÉ, Cempem - FE, Unicamp, v.16, n. 30, jul./dez. 2008.

VIDAL, D. G.. Escola Nova e processo educativo. In: LOPES, E. M.; FIGUEIREDO, L; e GREIVAS, C (orgs.). 500 anos de educação no Brasil. Belo Horizonte: Autêntica, $3^{a}$. Ed., 2003.

\section{Cintia Schneider}

Mestre em Educação Científica e Tecnológica - Universidade Federal de Santa Catarina. Catarina. Professora do Instituto Federal Catarinense - Câmpus Concórdia.Endereço: Ipumirim - SC, E-mail: cintia.schneider1995@gmail.com.

\section{David Antonio da Costa}

Professor do Departamento de Metodologia de Ensino de Centro de Ciências da Educação da Universidade Federal de Santa Catarina. Doutor em Educação Matemática. Endereço: Florianópolis SC, E-mail: david.costa@ufsc.br.

\section{Como citar este documento:}

SCHNEIDER, Cintia; DA COSTA, David Antonio. Os jogos para o ensino de aritmética no manual 'didática da $1^{\text {a }}$ série' de Amaral Fontoura. Reflexão e Ação, Santa Cruz do Sul, v. 28, n. 3, p. 181-194, ago. $2020 . \quad$ ISSN 1982-9949. Disponivel em: $<$ https://online.unisc.br/seer/index.php/reflex/article/view/11607>. Acesso em: doi:https://doi.org/10.17058/rea.v28i3.11607. 